\title{
Studies on the Inhibitive Effect of Exudate Gum from Dacroydes edulis on the Acid Corrosion of Aluminium
}

\author{
S.A. Umoren ${ }^{\mathrm{a}}$, I.B. Obot ${ }^{\mathrm{a},{ }^{*}, \text { E.E. Ebenso }}{ }^{\mathrm{b}}$, N. Obi-Egbedi ${ }^{\mathrm{c}}$ \\ ${ }^{a}$ Department of Chemistry, Faculty of Science, University of Uyo, Uyo, Nigeria \\ ${ }^{b}$ Physical Chemistry Unit, Department of Pure and Applied Chemistry, University of Calabar, \\ Calabar, Nigeria \\ Department of Chemistry and Chemical Technology, National University of Lesotho, \\ P.O.Roma 180, Lesotho, Southern Africa \\ ${ }^{c}$ Physical Chemistry unit, Department of Chemistry, University of Ibadan, Ibadan, Nigeria
}

Received 24 April 2007; accepted 13 June 2007

\begin{abstract}
The inhibitive effect of exudate gum from Dacroydes edulis in the corrosion of aluminium in $\mathrm{HCl}$ solutions was studied using weight loss and thermometric methods at $30-60{ }^{\circ} \mathrm{C}$. The results reveal that the exudate gum acts as an inhibitor for corrosion of aluminium in $\mathrm{HCl}$ solution. The inhibition efficiency increases with an increase in the concentration of the exudate gum but decreases with increase in temperature. The Temkim adsorption isotherm was tested for its fit to the experimental data. The result confirms that the corrosion inhibition of the exudate gum from DE is attributed to the adsorption of molecules of phytochemicals present in the exudate gum on the surface of the metal. The free energies and equilibrium constant for the adsorption process were determined. A mechanism of physical adsorption is proposed..
\end{abstract}

Keywords: corrosion inhibition, aluminium, Dacroydes edulis, adsorption, Temkin isotherm.

\section{Introduction}

Investigation of natural substances as corrosion inhibitors has attracted considerable attention because they have been shown to be cheap, ecologically friendly and possess no threat to the environment. Plant extracts including their leaves and tubers and their corrosion inhibitive properties have been widely examined. The inhibitive properties of Telfaria occidentalis extract [1], Occimum basilicum [2], Anacardium occidentale [3], Zenthoxylium alatum [4], Rosmarinus

\footnotetext{
* Corresponding author. E-mail address: proffoime@yahoo.com
} 
officinalis [5], Andrographis panizulata [6], Mimosa tannin [7], Prunus cerasus [8], Allium sativum [9], oil from Mentha pulegium [10], natural honey [11], extract of Rhizome powder [12], Lawsonia extract [13], Vernonia amydalina [14], Magnifera indica [15], Azadirachta indica [16,17], Carica papaya [17], Datura metel [18], have been reported. Also reported are the inhibitive effects of natural Artemisia oil [19] on steel and Jojoba oil [20] on aluminium in acidic medium. El-Etre has also reported on the effect of Khillah extract [21] and Opuntia extract [22] as ecofriendly corrosion inhibitors for steel and aluminium, respectively. Guar gum [23], Quinine [24] and Sansevieria trifasciata extract [25] have been shown to be effective corrosion inhibitors for metal in aggressive acid environments. Results obtained show that all the natural substances act as effective corrosion inhibitors in the different test media. Inhibition efficiency was found to increase with increase in the concentration of the tested materials. We have recently reported on the potential of Gum arabic as corrosion inhibitor for aluminium in alkaline medium [26]. The inhibition of aluminium corrosion by Gum arabic was attributed to the presence of arabinogalactan, oligosaccharides, polysaccharides and glucoproteins since these compounds contain oxygen and nitrogen atoms which are the centers of adsorption. It has also been shown by other researchers that the inhibitive effect of some plants solution extract is due to the adsorption of molecules of phytochemicals present in the plant on the surface of the metal [27-29].

Dacroydes edulis (DE) (pear tree) is widely planted and found mainly in tree crops fields and in home gardens in Nigeria, Cameroon and in Central Africa. The dead branches of the species are used as firewood and its bark is used as medicine [30]. This plant produces gummy exudates which are used locally. The present work is therefore another trial aimed at finding a cheap and environmentally safe inhibitor for aluminium corrosion in acidic medium using exudates gum from Dacroydes edulis.

\section{Experimental}

Pure aluminium metal (purity 98.5\%) of the type AA 1060 obtained from System Metals Industries Calabar, Nigeria, was used for the investigation. Each sheet was $0.4 \mathrm{~mm}$ in thickness and was mechanically press cut into $5 \mathrm{~cm} \times 4 \mathrm{~cm}$ coupons. These coupons were used in as cut condition, i.e., without further polishing. However, for surface treatment they were degreased in absolute ethanol, dried in acetone and stored in a desiccator devoid of moisture before use in corrosion studies. Dacroydes edulis (DE) was obtained locally. The impurities in the exudate gum, which are principally, sand, wood and bark fibres were removed by dissolving the exudate in hot $95 \%$ ethanol following the method of Ekpe et al. [31]. Thereafter, the gum was dried in an N53C-Genlab laboratory oven at $40{ }^{\circ} \mathrm{C}$ to obtain a solid gum. Different concentrations $(0.1$ to $0.5 \mathrm{~g} / \mathrm{L})$ of the exudate gum used as inhibitor was weighed and dissolved in $2 \mathrm{M} \mathrm{HCl}$. The concentration of $\mathrm{HCl}(\mathrm{BDH})$ used was $2 \mathrm{M}$. 


\section{Weight loss measurements}

In the weight loss experiments, a clean weighed aluminium coupon was immersed completely in a $250 \mathrm{~mL}$ beaker containing the corrodent and inhibitors with the aid of glass rods and hooks. The beakers were placed in a constanttemperature bath maintained at $30-60{ }^{\circ} \mathrm{C}$. The coupons were retrieved at $24 \mathrm{~h}$ interval progressively for $168 \mathrm{~h}$ (7 days), immersed in concentrated nitric acid (S.G 1.42) at room temperature, scrubbed with bristle brush under running water, dried in acetone and weighed [32,33]. The differences in weight of the coupons were taken as the weight loss which was used to compute the corrosion rate given by [33]

$$
\text { corrosion rate }(\mathrm{mm} / \mathrm{yr})=\frac{87.6 \mathrm{~W}}{\rho A t}
$$

where $W$ is the weight loss $\left(\mathrm{g} \mathrm{dm}^{-3}\right), \rho$ is the density of the specimen $(2.25 \mathrm{~g}$ $\left.\mathrm{cm}^{-3}\right)$, A the area of specimen $\left(\mathrm{cm}^{2}\right)$ and $t$ the exposure time (hrs).

The inhibition efficiency of $\mathrm{DE}$ acting as inhibitor in $2 \mathrm{M} \mathrm{HCl}$ was calculated using the following expression [17]:

$$
I(\%)=\left(1-\frac{W_{i}}{W_{0}}\right) \times 100
$$

where $W_{0}$ and $W_{1}$ are the weight losses of the aluminium coupons in the absence and presence of inhibitor, respectively, in $\mathrm{HCl}$ at the same temperature.

The degree of surface coverage $(\theta)$ was calculated using the expression [17]

$$
\theta=1-\frac{W_{i}}{W_{0}}
$$

\section{Thermometric measurements}

The reaction vessel and procedure for determining the corrosion behaviour by this method has been described elsewhere by other authors [34-36]. In the thermometric technique the corrodent $(\mathrm{HCl})$ concentration was kept at $2 \mathrm{M}$. The volume of test solution used was $50 \mathrm{~mL}$. The initial temperature in all experiments was kept at $30{ }^{\circ} \mathrm{C}$. The progress of corrosion reaction was monitored by determining the changes in temperature with time using a calibrated thermometer $\left(0-100{ }^{\circ} \mathrm{C}\right)$ to the nearest $\pm 0.05{ }^{\circ} \mathrm{C}$. This method enabled the computation of the reaction number $(\mathrm{RN})$ defined as $[26,34]$

$$
R N\left({ }^{o} C \min ^{-1}\right)=\frac{T_{m}-T_{i}}{t}
$$

where $T_{m}$ and $T_{i}$ are the maximum and initial temperatures, respectively, and ' $t$ ' is the time ( $\mathrm{min}$ ) taken to reach the maximum temperature. 


\section{Results and discussion}

\section{Effect of exudate gum on the corrosion rate}

The corrosion rates of the aluminium samples in $2 \mathrm{M} \mathrm{HCl}$ in the absence and presence of different concentrations of the exudate gum were determined. The results obtained are presented in Table 1. The corrosion rate decreases with increasing concentration of the gum. This indicates that the exudate gum in the solution inhibits the corrosion of aluminium in $\mathrm{HCl}$ and that the extent of corrosion inhibition depends on the amount of the extract present.

Table 1. Calculated values of corrosion rate ( $\mathrm{mm} / \mathrm{yr})$ and inhibition efficiency $(\% \mathrm{I})$ for exudate gum from weight loss data.

\begin{tabular}{|c|c|c|c|c|c|c|c|c|}
\hline \multirow{2}{*}{$\begin{array}{l}\text { Concentration } \\
\text { of } \mathrm{DE}(\mathrm{g} / \mathrm{L})\end{array}$} & \multicolumn{8}{|c|}{ Corrosion rate $(\mathrm{mm} / \mathrm{yr}) \times 10^{-3}$ and inhibition efficiency $(\% \mathrm{I})$} \\
\hline & \multicolumn{2}{|c|}{$30^{\circ} \mathrm{C}$} & \multicolumn{2}{|c|}{$40{ }^{\circ} \mathrm{C}$} & \multicolumn{2}{|c|}{$50{ }^{\circ} \mathrm{C}$} & \multicolumn{2}{|c|}{$60^{\circ} \mathrm{C}$} \\
\hline Blank & 5.1 & - & 11.0 & - & 12.0 & - & 16.0 & - \\
\hline 0.1 & $3.9^{\mathrm{a}}$ & $(22.0)^{\mathrm{b}}$ & 9.3 & (17.3) & 11.0 & (10.2) & 15.0 & (8.7) \\
\hline 0.2 & 3.7 & (27.0) & 8.6 & (24.1) & 10.0 & (17.3) & 14.0 & (16.0) \\
\hline 0.3 & 3.5 & (31.0) & 8.1 & (29.0) & 9.4 & (25.0) & 12.0 & (24.0) \\
\hline 0.4 & 3.3 & (38.0) & 7.2 & (34.0) & 8.3 & (33.0) & 11.0 & (32.0) \\
\hline 0.5 & 3.0 & (42.0) & 6.2 & (41.0) & 7.1 & (40.0) & 9.5 & (39.0) \\
\hline
\end{tabular}

(a) = corrosion rate obtained from equation (1)

(b) = inhibition efficiency (\% I) obtained using equation (2)

$\mathrm{DE}=$ Dacroydes edulis gum

Fig. 1 shows the variation of the inhibition efficiency with the concentration of the exudate gum. It is observed that the inhibition efficiency increases with increasing concentration of the gum. The maximum inhibition efficiency was observed to be $42 \%$ at $0.5 \mathrm{~g} / \mathrm{L}$ recorded at $30{ }^{\circ} \mathrm{C}$. The inhibitive effect of the Dacroydes edulis exudate gum could be attributed to the presence of some phytochemical constituents in the exudate. Previous studies have shown that the exudate gum contains tannin, oligosaccharides, polysaccharides and glucoproteins as part of its phytochemical composition [30,31]. Owing to the complex chemical composition of the exudate gum, it is quite difficult to assign the inhibitive effect to a particular constituent. 


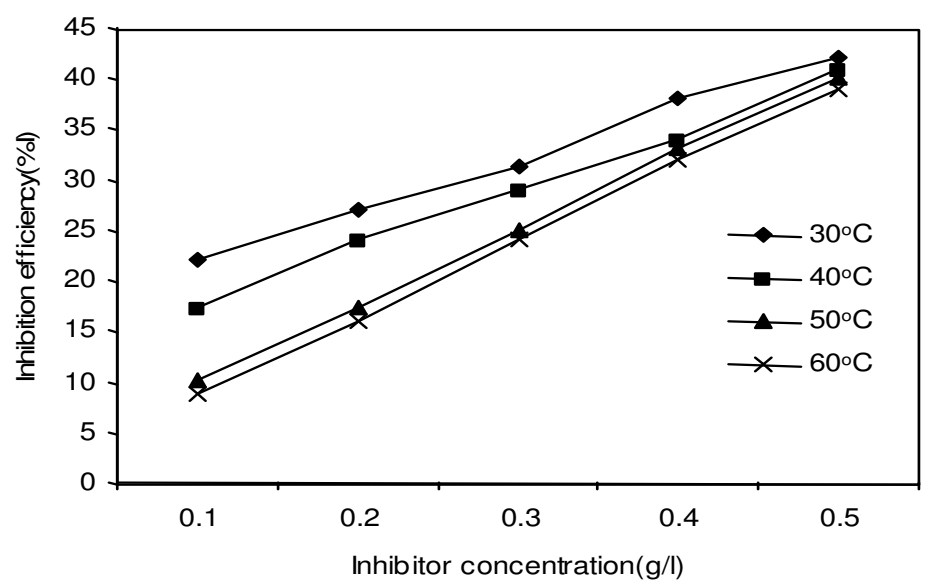

Figure 1. Variation of the inhibition efficiency with the concentration of DE gum for $\mathrm{Al}$ in $2 \mathrm{M} \mathrm{HCl}$ solution at $30-60{ }^{\circ} \mathrm{C}$.

\section{Kinetic analysis of weight loss results}

A plot of the logarithm of the measured weight of the aluminium against time, as depicted in Fig. 2, helps to explain the kinetics of the corrosion in $\mathrm{HCl}$ in the absence and presence of the inhibitors. Fig. 2 shows that a linear variation is observed from the plot both in the absence and presence of the gum, which confirms a first order kinetics which may be formulated as:

$$
\log W_{f}=\log W_{o}-k t
$$

where $W_{f}$ and $W_{o}$ are the weights of the coupons after and before immersion respectively, $k$ is the rate constant and $t$ is time [37].

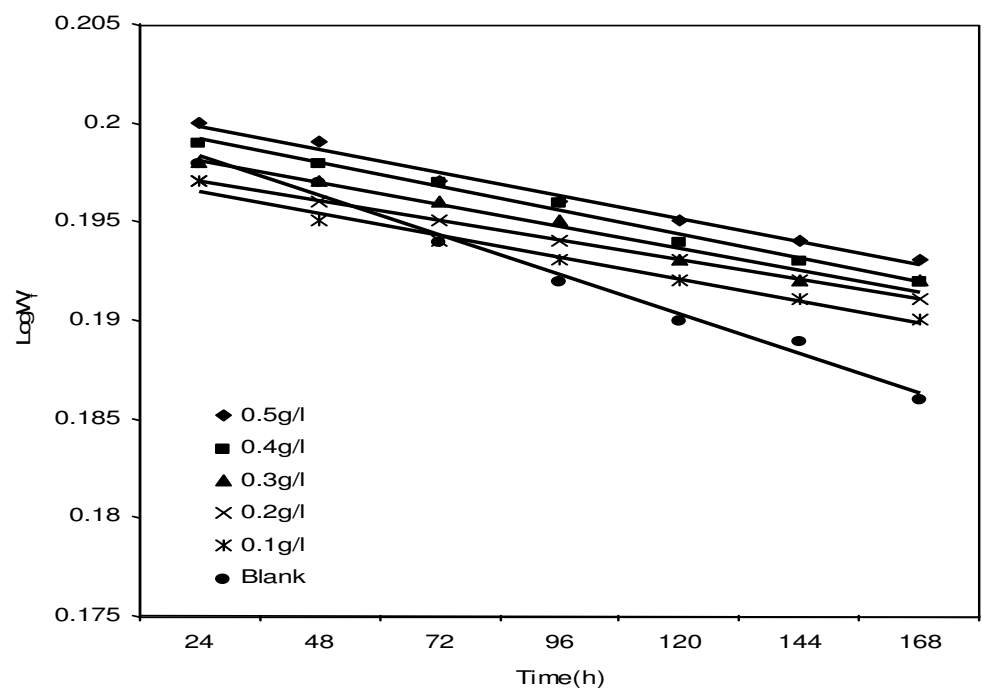

Figure 2. Plot of $\log \mathrm{W}_{\mathrm{f}}$ against time for $\mathrm{Al}$ in $2 \mathrm{M} \mathrm{HCl}$ solution in the absence and presence of exudate gum from Dacroydes edulis. 
Table 2. Kinetic and thermodynamic parameters for the corrosion of aluminium in $2 \mathrm{M}$ $\mathrm{HCl}$ solution containing exudate gum from Dacroydes edulis.

\begin{tabular}{|c|c|c|c|c|c|c|}
\hline \multirow{2}{*}{$\begin{array}{c}\text { Concentration } \\
\text { of DE }(\mathrm{g} / \mathrm{L})\end{array}$} & $\begin{array}{c}\text { Rate constant } \\
\mathrm{k}\left(\mathrm{s}^{-1}\right)\end{array}$ & $\begin{array}{c}\text { Half life } \\
(\mathrm{h})\end{array}$ & $\begin{array}{c}\text { Temp. } \\
\left({ }^{\circ} \mathrm{C}\right)\end{array}$ & \multicolumn{3}{|c|}{ Temkin isotherm } \\
\cline { 5 - 7 } & & & & $\Delta \mathrm{G}_{\text {ads }}^{\mathrm{o}}\left(\mathrm{kJmol}^{-1}\right)$ & $\mathrm{K}$ & $\mathrm{a}$ \\
\hline & & & & & & \\
Blank & 7.2 & 346 & & - & - & - \\
0.1 & 3.9 & 630 & 30 & -18.2 & 1.9 & -0.3 \\
0.2 & 3.6 & 693 & 40 & -17.8 & 1.7 & -0.3 \\
0.3 & 3.9 & 630 & 50 & -17.4 & 1.5 & -0.2 \\
0.4 & 4.3 & 576 & 60 & -16.8 & 1.5 & -0.4 \\
0.5 & 4.3 & 576 & & & & \\
& & & & & & \\
\hline
\end{tabular}

The values of the rate constants obtained from the slope in Fig. 2 are presented in Table 2. It was observed that the rate constants vary linearly with the logarithm of the exudate gum concentration, c, as depicted in Fig. 3, and obeys the relationship:

$$
k=-0.204 c+4.476
$$

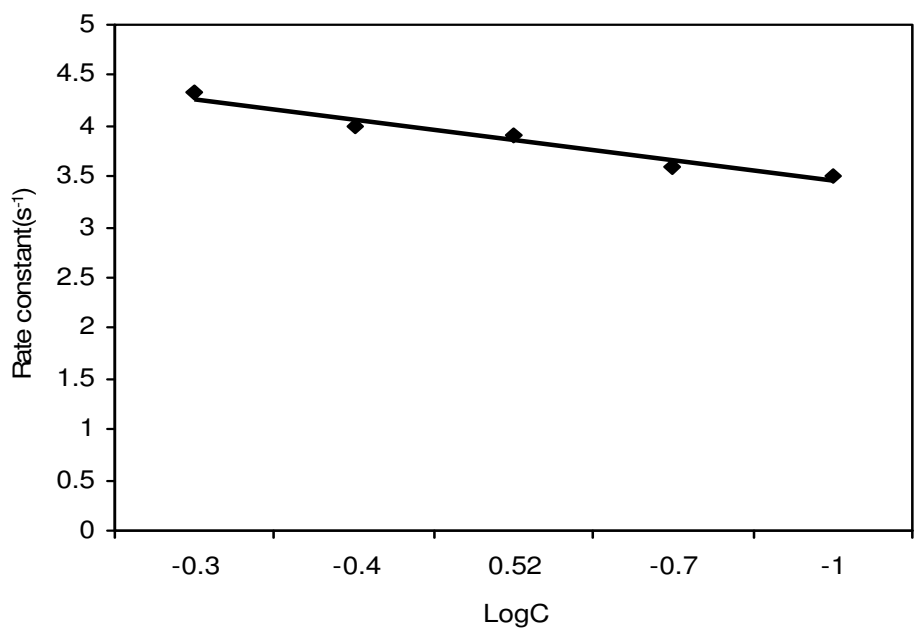

Figure 3. Plot of rate constant against $\log \mathrm{C}$ for $\mathrm{Al}$ in $2 \mathrm{M} \mathrm{HCl}$ solution containing $\mathrm{DE}$ gum.

From values of the rate constants, half-life of corrosion reaction involving aluminium in the absence and presence of different concentrations of the exudate gum were estimated. The values are also presented in Table 2. It was found to be linearly dependent on the concentration of the gum, decreasing with increase in the concentration of the exudate gum as shown in Fig. 4. A similar trend has earlier been reported [38,39]. The results obtained are not very clear. However, it is assumed that adsorbed organic molecule can influence the behaviour of electrochemical reactions involved in corrosion processes in several ways. The action of organic inhibitor also depends on the type of interactions between the 
substance and the metallic surface. The interaction can bring about a change either in electrochemical mechanism or in the surface available for the processes [40]. The half-life obeys the relationship:

$$
t_{1 / 2}=-22.5 c+688.5
$$

where $\mathrm{c}$ is the concentration of the exudate gum.

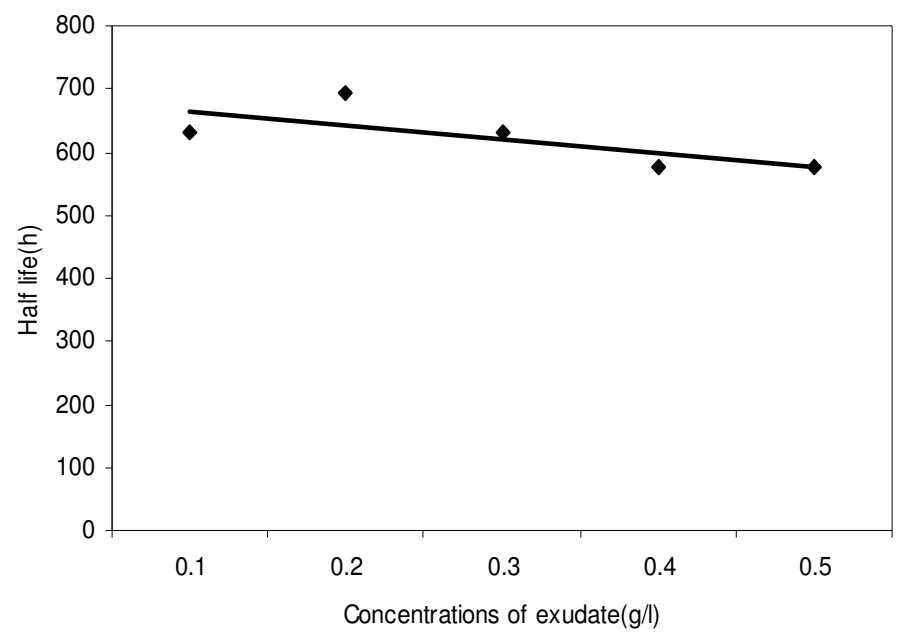

Figure 4. Variation of the half-life with the concentration of exudate gum from DE for $\mathrm{Al}$ in $2 \mathrm{M} \mathrm{HCl}$ solution at $30{ }^{\circ} \mathrm{C}$.

\section{Adsorption studies}

The mechanism of the interaction between inhibitor and the metal surface can be explained using adsorption isotherms. The degree of surface coverage, $\theta$, for the different systems studied was computed from the weight loss measurements. The surface coverage values for the tested exudate gum obtained from Dacroydes edulis was applied to various adsorption isotherm models. It was found that the experimental data fitted the Temkin adsorption isotherm, which may be formulated as [17]

$$
\exp (-2 a \theta)=K C
$$

where ' $a$ ' is the molecules interaction parameter, $\theta$, is the degree of surface coverage, ' $\mathrm{K}$ ' is equilibrium constant of adsorption process and ' $\mathrm{C}$ ' is the concentration of the inhibitor. Fig. 5 shows the plot of $\theta$ against $\log \mathrm{C}$ for the exudate at 30-60 ${ }^{\circ} \mathrm{C}$ (Temkin adsorption isotherm). Linear plots were obtained indicating that the experimental results fit the Temkin isotherm. This result confirms that the corrosion inhibition of the exudate gum from DE is attributed to the adsorption of molecules of phytochemicals present in the exudate gum on the surface of the metal. The calculated values of molecular interaction parameter 'a' and equilibrium constant of adsorption process, $\mathrm{K}$ obtained from Temkin plot are shown in Table 2. The values of 'a' are negative in all cases showing that repulsion exist in adsorption layer [41]. 


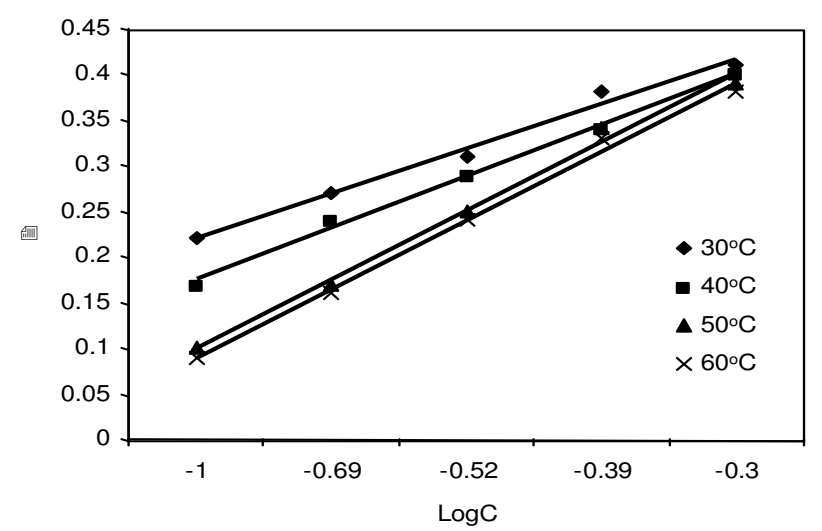

Figure 5. Temkin adsorption isotherm for $\mathrm{Al}$ in $2 \mathrm{M} \mathrm{HCl}$ solution containing DE gum at $30-60{ }^{\circ} \mathrm{C}$.

The thermodynamic parameters for adsorption shown in Table 2 were calculated using the values of $\mathrm{K}$ according to the following equation [29]

$$
\Delta G_{a d s}^{o}=-R T \ln (K x 55.5)
$$

The values obtained are presented in Table 2 . The values of $\Delta G_{a d s}^{o}$ indicate that the inhibitors function by physically adsorbing on the metal. The adsorption of these compounds on the aluminium surface reduces the surface area available for corrosion. Generally, values of $\Delta G_{a d s}^{o}$ up to $-20 \mathrm{kJmol}^{-1}$ are consistent with electrostatic interaction between charged molecules and a charged metal (which indicates physical adsorption), while those more negative than $-40 \mathrm{kJmol}^{-1}$ involve charge sharing or transfer from the inhibitor molecules to the metal surface to form a co-ordinate type of bond (which indicates chemisorption) $[24,26]$. Further work on the mechanistic aspect of the corrosion inhibition of exudate gum from Dacroydes edulis can be better understood using electrochemical studies such as polarization and AC impedance spectra. Also addition of halides may improve the performance of the inhibitor significantly as reported elsewhere [1,2,25]

\section{Thermometric measurements}

Thermometric methods have proved useful in evaluating the inhibitor efficiency of a number of surface-active agents and results obtained using these techniques are corroborated by other well-established methods such as weight loss, potentiostatic polarization measurements [34]. 


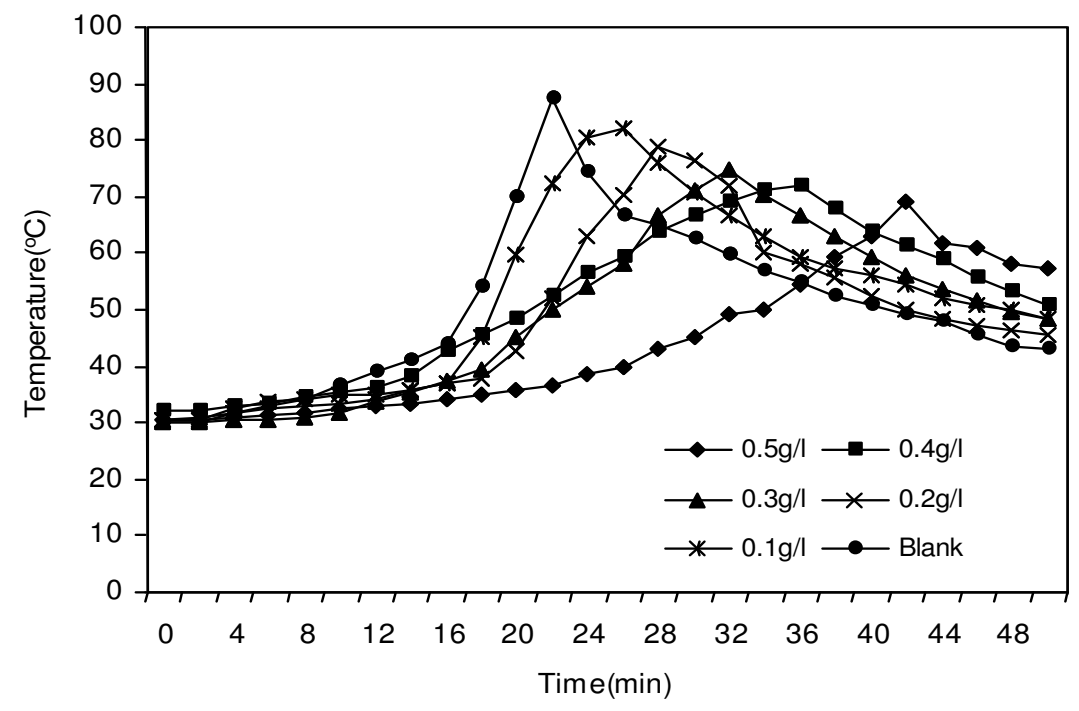

Figure 6. Temperature - time curves for the dissolution of aluminium in blank and different concentrations of the exudate gum.

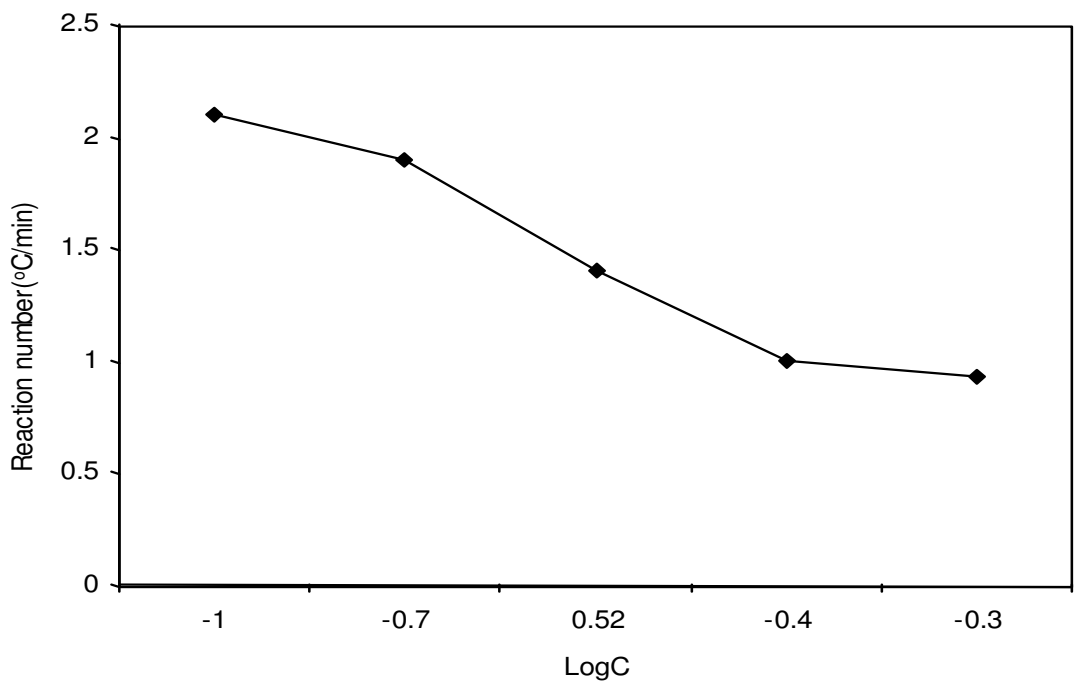

Figure 7. Plot of RN against Log of inhibitor concentration.

Fig. 6 shows the temperature-time curves for the dissolution of aluminium in $2 \mathrm{M}$ $\mathrm{HCl}$ in the absence and in the presence of different concentrations of the inhibitor (DE). Inspection of Fig. 6 shows that as the concentration of the inhibitor increases, the time required to reach maximum temperature $\left(T_{m}\right)$ increases and the rate of temperature rise decreases, that is, the inhibition efficiency increases with the increase in the concentration of the inhibitor. Fig. 7 shows the relationship between the $\mathrm{RN}$ and the logarithm of inhibitor concentration. The curve consists of an initial decreasing portion along which the $\mathrm{RN}$ decreases with increasing concentration of DE and then the rate of decrease became smaller. As the concentration of DE increased further, the value of RN decreased with 
concentration. This is an indication that the exudate gum inhibits the corrosion of $\mathrm{Al}$ in the acidic environment, probably by adsorption on the metal surface [26].

\section{Conclusions}

From the experimental results obtained in the present study, the following conclusions could be drawn:

1. Dacroydes edulis exudate gum acts as inhibitor for aluminium corrosion in HCI solution.

2. Inhibition efficiency increased with increase in concentration of the Dacroydes edulis exudate gum but decreased with increase in temperature which confirmed that the adsorption process was physical in nature. Phytochemical constituents in the exudate play a very vital role in the inhibiting action.

3. Phenomenon of physical adsorption is proposed from the calculated values of $\Delta G_{a d s}^{o}$. The values were negative which suggests that DE exudate gum was strongly adsorbed on the metal surface. The values of $\Delta G_{a d s}^{o}$ at all temperatures studied indicate spontaneous adsorption of the inhibitor, and this is usually characteristic of strong adsorption with the metal surface.

4. Kinetic analysis of the data showed a linear variation, which confirms a first order kinetics.

5. The adsorption process for Dacroydes edulis exudate gum followed the Temkin adsorption isotherm.

\section{References}

1. E.E. Oguzie, Pigment \& Resin Tech. 34(6) (2005) 321.

2. E.E. Oguzie, A.I. Onuchukwu, P.C. Okafor, E.E. Ebenso, Pigment \& Resin Tech. 35(2) (2006) 63.

3. C.A. Loto, A.I. Mohammed, Corros. Prev. Control 47 (2) (2000) 50.

4. G. Gunasekeran, L.R. Chauhan, Electrochimica Acta 49 (25) (2004) 4387.

5. M. Kliskic, J. Radosevic, S. Gudic, V. Katalinic, J. Appl. Electrochem. 30 (2000) 823.

6. $\quad$ G.O. Avwiri, F.O. Igbo, Mater. Lett. 57 (2003) 3705.

7. $\quad$ S. Martinez, I. Stern, J. Appl. Electrochem. 33 (2001) 1137.

8. H. Ashassi-Sorkhabi, D. Seifzadeh, Int. J. Electrochem. Sci. 1 (2006) 92.

9. P.C. Okafor, U.J. Ekpe, E.E. Ebenso, E.M. Umoren, K.E. Leizou, Bull. Electrochem. 21(8) (2005) 347.

10. A. Bouyanzer, B. Hammouti, L. Majidi, Mater. Lett. 60 (2006) 284.

11. A.Y. El-Etre, Corros. Sci. 40 (11) (1998) 1845.

12. S. Rajendran, S. Shanmugapriya, T. Rajalakshmi, A.J. Amal Raj, Corrosion 61 (7) 685.

13. A.Y. El-Etre, M. Abdallah, Z.E. El-Tantawy, Corros. Sci. 47 (2) 385.

14. S.P. Ramesh, K.P. Vinod, G.H. Sethhuraman, Bull. Electrochem. 17 (3) (2001) 141. 
15. C.A. Loto, A.I. Mohammed, R.O. Loto, Corros. Prev. Control, 50 (30) (2003) 107.

16. E.E. Oguzie, Pigment \& Resin Tech. 35(6) (2006) 334.

17. E.E. Ebenso, U.J. Ibok, U.J. Ekpe, S.A. Umoren, E. Jackson, O.K. Abiola, N.C. Oforka and S. Martinez, Trans. SAEST 39 (2004) 117.

18. M.G. Sethuraman, P.B. Raja, Pigment \& Resin Tech. 34(6) (2005) 327.

19. A. Bouyanzer, B. Hammouti, Pigment \& Resin Tech. 33(5) (2004) 287.

20. A. Chetouani, B. Hammouti, M. Benkaddour, Pigment \& Resin Tech. 33(1) (2004) 26.

21. A.Y. El-Etre, Appl. Surf. Sci. 252 (2006) 8521.

22. A.Y. El-Etre, Corros. Sci. 45 (2003) 2485.

23. M. Abdallah, Portugaliae Electrochimica Acta 22 (2004) 161.

24. M.I. Awad, J. Appl. Electrochem. 36 (2006) 1163.

25. E.E. Oguzie, Corros. Sci. 49 (2007) 1527.

26. S.A. Umoren, I.B. Obot, E.E. Ebenso, P.C. Okafor, O. Ogbobe, E.E. Oguzie, Anti-Corros. Methods and Mater. 53(5) (2006) 277.

27. S.J. Zakvi, G.N. Mehta, Trans. SAEST 23 (1988) 4.

28. S. Martinez, Mater. Chem. Phys. 77 (2002) 97.

29. A.Y. El-Etre, Z. El-Tantawy, Portugaliae Electrochimica Acta 24(2006) 347.

30. E.T. Ayuk, B. Duguma, S. Franzel, J. Kengue, M. Mollet, T. Tiki-Manga, P. Zekeng, Economic Botany 53(3) (1999) 292.

31. U.J. Ekpe, E.E. Ebenso, B.S. Antia, West. Afri. J. Biol. Appl. Chem. 41 (1999) 16.

32. Corrosion Basics, “An Introduction”, National Association of Corrosion Engineers (NACE) (1984) 34.

33. D.A. Jones, "Principles and Prevention of Corrosion", $2^{\text {nd }}$ Edition, Printice-Hall Inc., Upper Saddle River, NJ USA, 1996 Pp 31-34.

34. B.N. Oza, R.S. Sinha, Trans. SAEST 17(1) (1982) 281.

35. A.A. Shams Eldin, M.G.A. Kherdr, Metalloberft 25 (1992) 200.

36. A.Y. El-Etre, Corros. Sci. 43 (2001) 1031.

37. P. Atkins, J. de Paula, Physical Chemistry, Oxford University Press, Oxford (2002) 871.

38. I. Ita, O.E. Offiong, Mater. Chem. Phys. 70 (2001) 330.

39. E.E. Ebenso, P.C. Okafor, O.E. Offiong, B.I. Ita, U.J. Ibok, U.J. Ekpe, Bull. Electrochem. 17 (2001) 459.

40. S.M. Mayanna, J. Electrochem. Soc. 122 (1973) 252.

41. L. Tang, X. Li, Y. Si, G. Mu, G. Liu, Mater. Chem. Phys. 95 (2006) 29. 